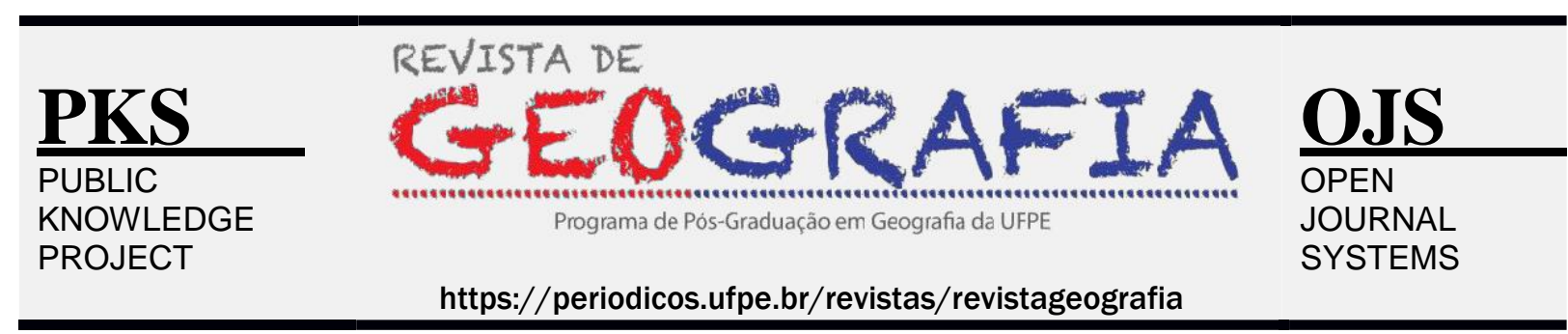

\title{
ANÁLISE DA PERCEPÇÃO AMBIENTAL DOS MORADORES DO ENTORNO DO AÇUDE JATOBÁ II NO MUNICÍPIO DE PRINCESA ISABEL-PB
}

\author{
Dalva Damiana Estevam da Silva ${ }^{1}$, Fábio Remy de Assunção Rios ${ }^{2}$, João Miguel \\ de Moraes Neto ${ }^{3}$
}

\begin{abstract}
${ }^{1}$ Mestra em Engenharia Agrícola pelo Programa de Pós-Graduação em Engenharia Agrícola/Irrigação e Drenagem (PPGEA),UFCG, E-mail: dalvaestevamifpb@gmail.com

${ }^{2}$ Doutor em Ciência e Engenharia de Materiais pelo Programa de Pós-Graduação de Engenharia de Materiais (PPGMET), UFCG, E-mail: fabioremy@gmail.com

${ }^{3}$ Professor do Departamento de Engenharia Agrícola da Universidade Federal de Campina Grande (UFCG),

E-mail:moraes@deag.ufcg.edu.br
\end{abstract}

Artigo recebido em 03/11/2017 e aceito em 23/11/2019

\begin{abstract}
RESUMO
Os estudos sobre a percepção ambiental possibilitam compreender a relação do homem com o meio ambiente. Nesse processo a participação dos diversos atores da sociedade é fundamental para a detecção dos problemas ambientais. O objetivo desse trabalho foi analisar a percepção ambiental dos moradores do entorno do açude Jatobá II no município de Princesa Isabel-PB. A metodologia envolveu a aplicação de questionários semiestruturados a população residente no entorno do açude. Os resultados mostram que a população desconhece temas relacionados ao meio ambiente, mesmo convivendo com a problemática ambiental. Durante o trabalho de campo muitos moradores reclamavam do mau cheio provindo dos resíduos agroindustriais depositados em um terreno nas proximidades de um dos riachos que deságuam no açude Jatobá II. Apesar dos problemas existentes nas imediações do açude a percepção ambiental dos moradores mostra-se limitada, fato que merece maior atenção por parte da sociedade e pelos órgãos públicos, pois afetam a qualidade de vida da população residente nesta área.
\end{abstract}

Palavras-chave: Percepção; Problemas Ambientais; Resíduos Agroindustriais; População.

\section{ANALYSIS OF THE ENVIRONMENTAL PERCEPTION OF THE RESIDENTS OF THE SURROUNDINGS OF THE RESERVOIR JATOBÁ II IN THE MUNICIPALITY OF PRINCESA ISABEL-PB}

\begin{abstract}
Studies on environmental perception make it possible to understand the relationship between man and the environment. In this process the participation of the various actors in society is fundamental for the detection of environmental problems. The objective of this study was to analyze the environmental perception of the residents of the surroundings of the Jatobá II reservoir in the municipality of Princesa Isabel-PB. The methodology involved the application of semi-structured questionnaires to the resident population around the reservoir. The results show that the population is unaware of environmental themes, same even living with environmental problems. During the field work many residents complained about the bad full of the agroindustrial residues deposited in vicinity in the drain streams in the reservoir Jatobá II. Despite the problems in the vicinity of the dam, the environmental perception of the residents is limited, a fact that deserves greater attention of the society and the public organs, since they affect the quality of life of the resident population in this area.
\end{abstract}

Keywords: Perception; Environmental Problems; Agroindustrial Residues; Population. 


\section{INTRODUÇÃO}

Ao longo das décadas o consumo desenfreado dos recursos naturais gerou inúmeras consequências ao meio ambiente. As atividades humanas provocaram desequilíbrio nos ecossistemas, degradação da qualidade ambiental, poluição e escassez dos recursos hídricos. Esses problemas em sua grande maioria são ocasionados ou agravados pelo homem, afetando a qualidade de vida da população.

A forma como o indivíduo percebe a natureza pode influenciar positivamente ou negativamente suas ações. A percepção ambiental provém do conhecimento obtido através da cultura, dos grupos socioeconômicos, das desigualdades e realidades que influenciam diretamente a forma como a natureza é percebida pelo homem.

Nesse processo é fundamental a compreensão do meio, da paisagem e da realidade ao qual está inserido. Entretanto, "a percepção ambiental deve estar atenta e centrada nas inúmeras diferenças relacionadas às percepções, aos valores existentes entre os indivíduos que compõem o cenário de [...] um lugar" (MELAZO, 2005, p. 3).

Neste contexto, a percepção ambiental pode ser definida como o produto da reação dos sentidos diante do meio que cerca o indivíduo, possibilitando o seu raciocínio, a definição de valores, sentimentos, reações e interações positivas ou negativas sobre o ambiente. A partir dessa percepção, o indivíduo interage com o mundo, influencia seus pares, intervém no ambiente, caminha na direção do processo de conhecimento e do exercício da cidadania ambiental (FERNANDES et al., 2009).

As alterações realizadas no ambiente pelo homem estão ligadas a forma como este percebe e se comporta no ambiente. Neste sentido, o açude Jatobá II, localiza-se no município de Princesa Isabel no Estado da Paraíba e passa por mudanças impulsionadas pelas atividades agropecuárias, agroindustriais e urbanização.

O desmatamento é realizado principalmente nas imediações do reservatório e em áreas serranas, onde a vegetação está sendo substituída por capim para alimentação animal. A urbanização é realizada de forma desordenada e sem planejamento contribuindo para a poluição proveniente de resíduos sólidos e efluentes domésticos. Além disso, os resíduos agroindustriais (granjas) contribuem para o aumento da poluição, seja do ar, dos recursos hídricos e do solo.

Os estudos sobre o meio ambiente são fundamentais para a detecção dos fatores que propagam a degradação, bem como para "apontar o melhor caminho para se enfrentar e controlar os danos ambientais dentro de determinadas comunidades" (CARVALHO e RODRIGUES, 2015, p. 26). 
Por meio do estudo da percepção é possível conhecer cada um dos grupos envolvidos, facilitando a realização de um trabalho com bases locais, partindo da realidade do público alvo, para conhecer como os indivíduos percebem o ambiente em que convivem, suas fontes de satisfação e insatisfação (FAGGIONATO, 2011).

Dessa forma, a detecção de problemas ambientais pode auxiliar o poder público no desenvolvimento e ações mitigadoras que minimizem ou solucionem a problemática. Esse trabalho teve como objetivo analisar a percepção ambiental dos moradores residentes no entorno do açude Jatobá II no município de Princesa Isabel-PB. Nesse processo a participação e colaboração de todos os atores da sociedade, principalmente aqueles que vivenciam de perto a problemática ambiental se torna essencial, para que sejam desenvolvidas ações públicas eficazes.

\section{MATERIAL E MÉTODOS}

\section{Localização geográfica e caracterização da área de estudo}

O município de Princesa Isabel, está localizado na região Oeste do Estado da Paraíba, Mesorregião do Sertão e Microrregião da Serra Teixeira (Figura 1). O município possui 21.283 habitantes, com uma área de $368 \mathrm{~km}^{2}$ (IBGE, 2010). A sede municipal apresenta altitude de 680m e coordenadas geográficas de $37^{\circ} 59^{\prime} 34^{\prime \prime}$ longitude Oeste e $07^{\circ} 44^{\prime} 13^{\prime \prime}$ de latitude Sul (MASCARENHAS et al., 2005).

Figura 1- Localização da área de estudo.

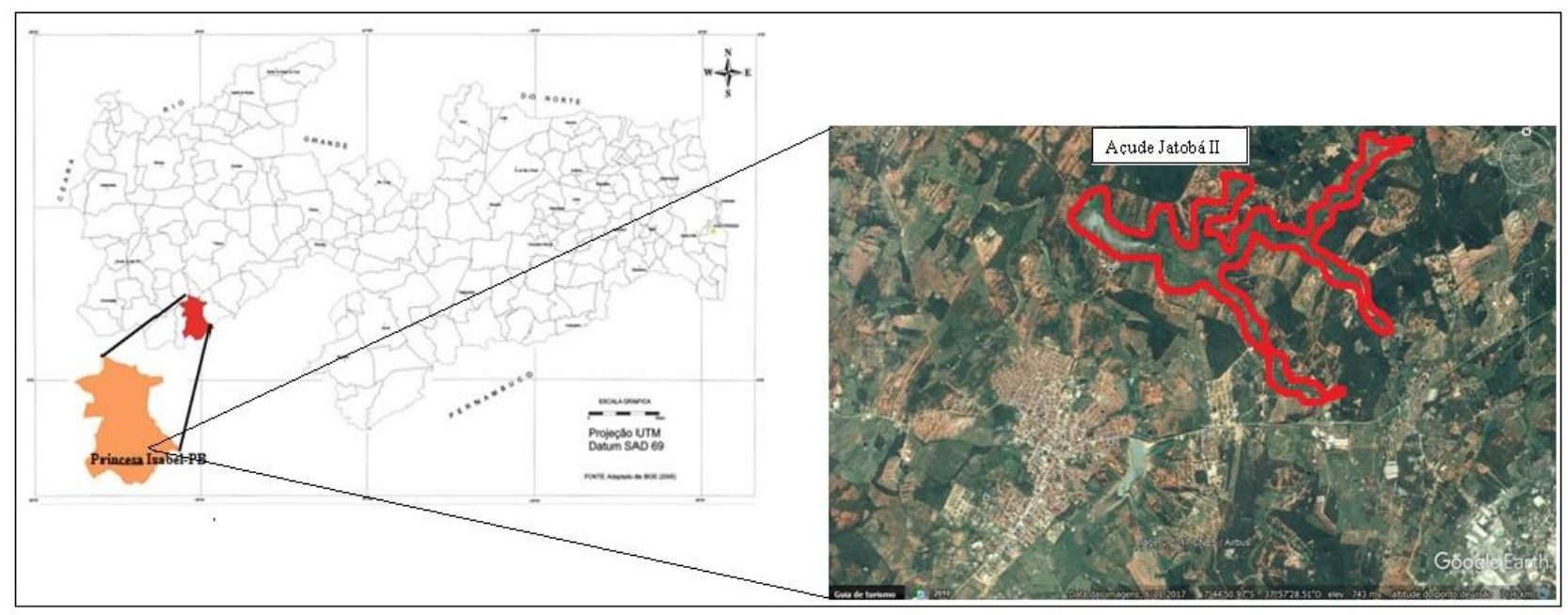

Fonte: Adaptado do IBGE (2009) e Google Earth (2017).

O clima predominante no município de acordo com a classificação de Köppen é do tipo Aw' - quente e úmido com chuvas de verão-outono (BRASIL, 1972). Conforme Mascarenhas et al., (2005) durante o dia as temperaturas são elevadas, sendo mais amenas à noite, com variações 
anuais entre 23 e $30^{\circ} \mathrm{C}$.

O regime pluviométrico, além de baixo é irregular com médias anuais em torno de 789,2mm/ano e mínimas e máximas de 287,4 e 2395,9 mm/ano respectivamente. No geral caracteriza-se pela presença de apenas 02 estações: a seca que constitui o verão e a chuvosa denominada pelo sertanejo de inverno. Convém frisar, que devido à variação do relevo o índice pluviométrico da microrregião compreendida entre Manaíra e Teixeira é maior que o das outras áreas do Oeste paraibano (MASCARENHAS et al., 2005).

O açude Jatobá II está localizado a aproximadamente $5 \mathrm{~km}$ da zona urbana do município de Princesa Isabel, teve sua construção iniciada em 10 de dezembro de 1954 e concluída em dezembro de 1956, com capacidade de armazenamento inicial de $7.600 .000 \mathrm{~m}^{3}$, conforme a Agência Executiva de Gestão das Águas do Estado da Paraíba (AESA, 2015). Suas águas são utilizadas no abastecimento público. Na zona rural as águas do reservatório são usadas para dessedentação animal, abastecimento das residências, irrigação, bem como, plantação de forragens para alimentação animal. Em 2015 o açude entrou em colapso, atualmente o volume hídrico corresponde a $166.061 \mathrm{~m}^{3}$ (AESA, 2019).

\section{Procedimentos metodológicos}

A verificação dos níveis de percepção ambiental dos moradores do entorno do açude Jatobá II, realizou-se através da aplicação de questionários para entender como os entrevistados compreendem questões de cunho ambiental.

Para avaliar a percepção ambiental da população da área, foram realizadas visitas e aplicados 14 questionários semiestruturados contendo questões abertas e fechadas, a 10\% do total dos moradores residentes no entorno do açude.

No período de realização da pesquisa, que ocorreu entre os meses de dezembro de 2015 e abril/maio de 2016, a área objeto de estudo estava sem Agente Comunitário de Saúde (ACS). A aplicação dos questionários foi realizada com as pessoas que se encontravam nas residências.

Durante o trabalho de campo realizou-se o registro fotográfico da área para melhor compreensão da problemática ambiental. A coleta de dados permitiu a elaboração do diagnóstico da percepção ambiental dos moradores acerca das questões ambientais.

\section{RESULTADOS E DISCUSSÃO}

\section{Perfil socioeconômico dos moradores do entorno do açude Jatobá II}

Os dados mostram que entre os entrevistados $64 \%$ são do sexo masculino e $36 \%$ são do sexo feminino. A faixa etária dos entrevistados variou entre 13 e 79 anos. A renda familiar varia 
entre 1 e 2 salários mínimos, sendo que a maioria 64,3\% corresponde a aposentadoria, 7,1\% possuem renda superior a 6 salários mínimos e $28,6 \%$ possuem renda inferior a um salário mínimo.

O grau de escolaridade dos entrevistados é baixo, 14\% são analfabetos, 36\% possuem ensino fundamental incompleto, $36 \%$ possuem o ensino fundamental completo, $7 \%$ possuem o ensino médio completo e o $7 \%$ tem o ensino superior completo.

Com relação ao tempo de moradia 7,1\% residem a menos de 1 ano, 28,6\% entre 2 e 4 anos, $7,1 \%$ entre 10 e 14 anos, $14,4 \%$ de 15 a 20 anos e $21,4 \%$ residem no local a mais de 20 anos. "O tempo de residência no local além de fornecer informações sobre a dinâmica da população é uma das variáveis que pode influenciar a forma como os indivíduos se relacionam com o ambiente em que vivem" (CARVALHO e RODRIGUES, 2015, p. 29).

\section{Percepção ambiental dos moradores do entorno do açude Jatobá II}

A percepção dos entrevistados sobre o meio ambiente é significativa, onde 71,4\% afirmaram ter conhecimento sobre o que seja meio ambiente e $28,6 \%$ não sabem o que significa (Figura 2). A propagação de informações de cunho ambiente ganha um espaço cada vez maior, pois são disseminadas pelos meios de comunicação que tem dado maior atenção às questões ambientais e a preocupação com o meio ambiente.

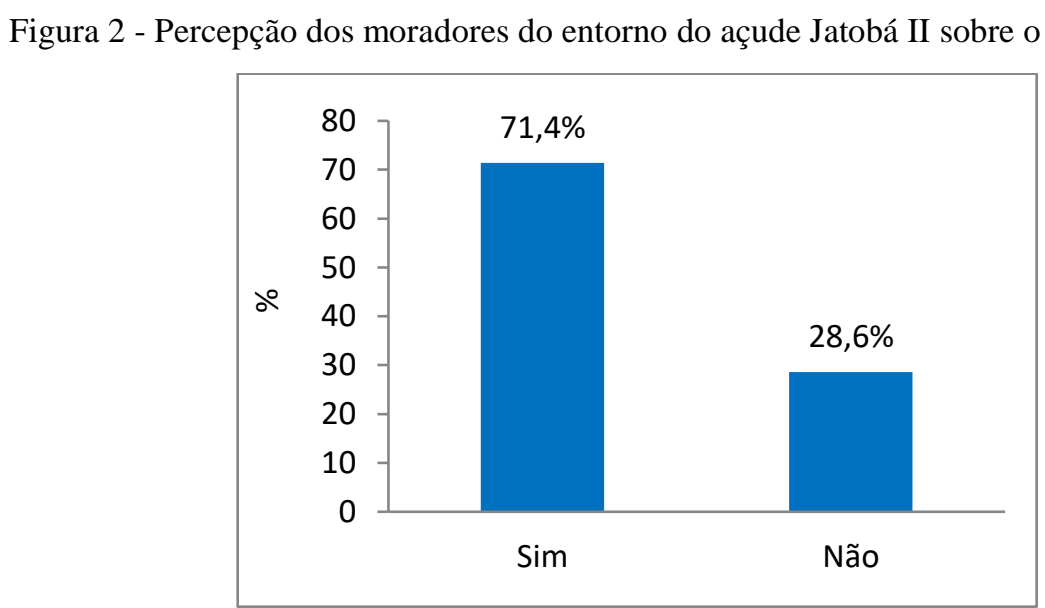

Fonte: Elaborado pelos autores (2016).

Com relação aos problemas ambientais no município, 92,9\% dos entrevistados responderam que existem problemas ambientais na área municipal, enquanto que, 7,1\% afirmaram não existir problemas desse tipo no município (Figura 3). 
Revista de Geografia (Recife) V. 36, No.3, 2019 - ISSN: 2238-6211

Figura 3 - Existência de problemas ambientais no município de Princesa Isabel-PB.

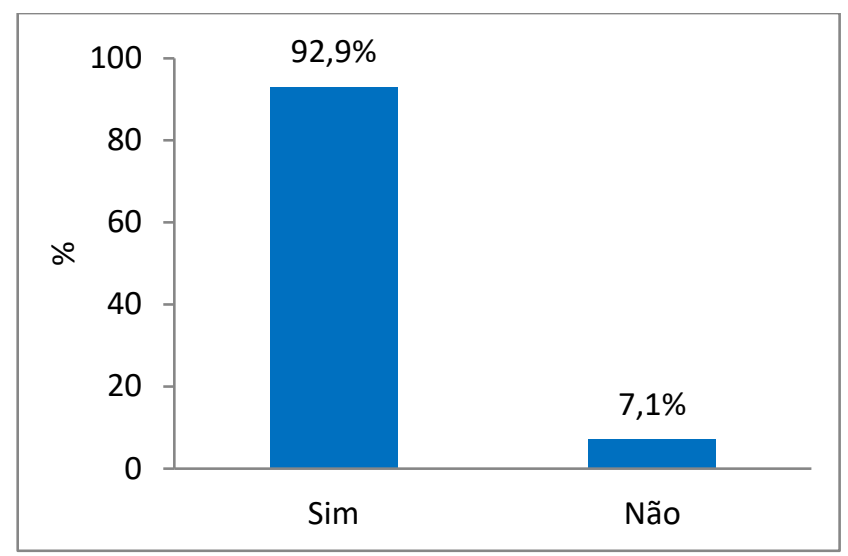

Fonte: Elaborado pelos autores (2016)

Durante a pesquisa de campo, percebeu-se que muitos moradores questionavam alguns problemas existentes no entorno do açude Jatobá II, a exemplo dos resíduos de agroindustriais (granjas), vários moradores reclamaram do mau cheiro gerado pelos dejetos.

O mau cheiro provém da deposição dos resíduos das granjas existentes no município, que expandiram suas instalações ao longo dos anos (Figura 4). A agroindústria gera inúmeros empregos no município que beneficiam muitas pessoas, no entanto, essa é uma atividade geradora de muitos impactos ambientais negativos, seja no solo, nos recursos hídricos ou no ar.

Figura 4 - Localização dos galpões instalados para criação de galinhas (granjas) no município de Princesa Isabel-PB.

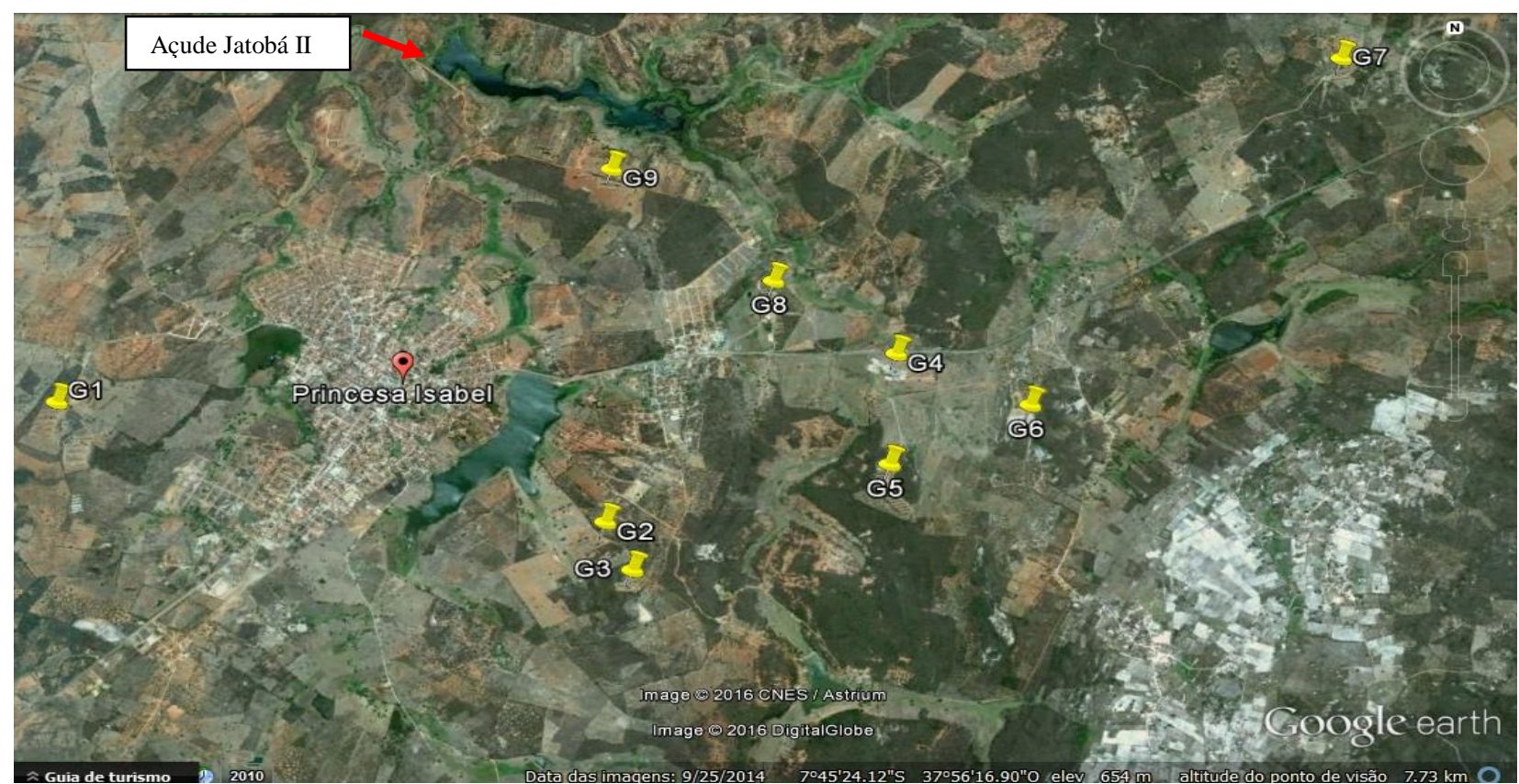

Fonte: Google Earth (2016).

No município atuam duas granjas que possuem diversos galpões espalhados pela área municipal. Informações coletadas durante o trabalho de campo mostram que uma das granjas 
deposita os dejetos em um local inapropriado, onde ficam expostos a céu aberto, ocasionando em desconforto para a população que vive no entorno do açude (Figura 5).

Figura 5 - A) Resíduos provindos de granjas e B) Caminhão sendo abastecido com resíduos.
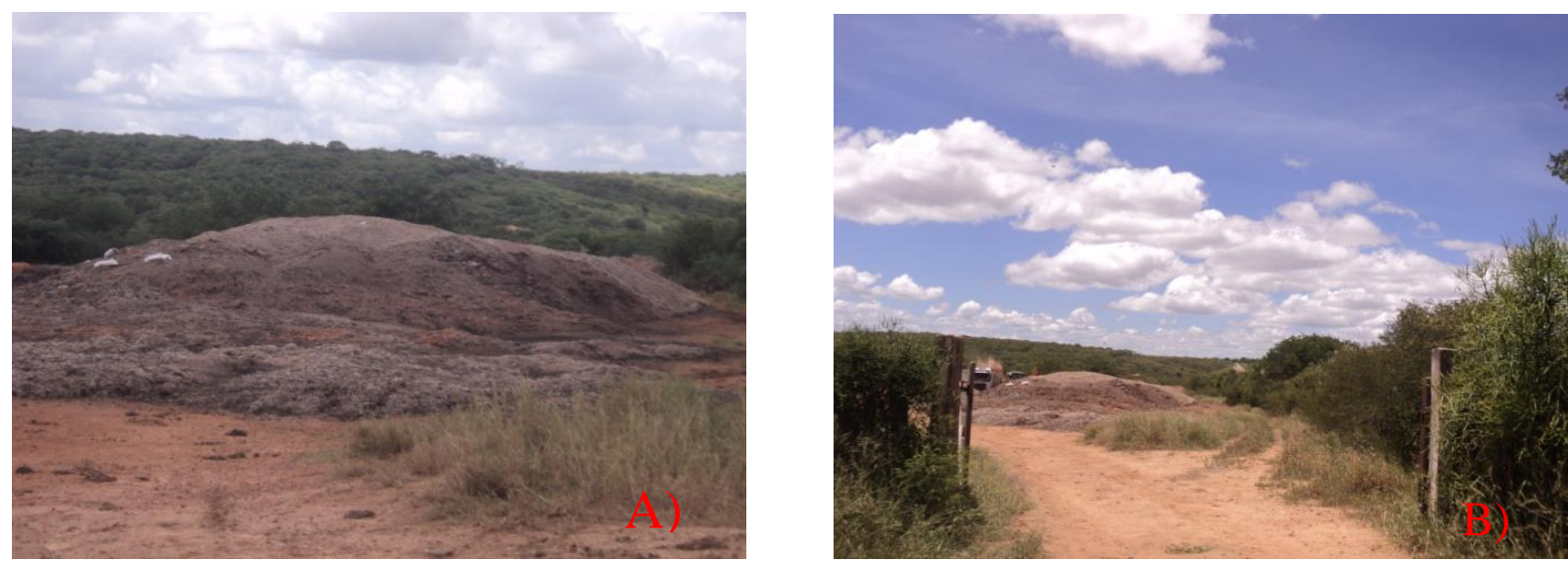

Fonte: A autora (2016).

Segundo os próprios moradores a situação piora quando chove. Estes resíduos são depositados neste mesmo local há anos e é alvo constante de reclamação por parte dos moradores que não concordam com a deposição dos dejetos no local. Os resíduos são compostos por fezes, restos de ração dentre outros resíduos, que são comercializados para adubação de terras.

Ferreira (2010) ressalta que o gás gerado da degradação do excremento das aves nas camas de galinha é a amônia. A cama de galinha tem a função de reter as fezes, restos de alimentos, descamações da pele, penas e a umidade no decorrer da produção, tornando-se assim, após seu uso, um dos principais resíduos do sistema de produção de frangos de corte com potencial poluidor do ambiente (BADO, 2006).

Os principais reflexos ambientais relacionados à emissão e dispersão de gases a partir das instalações de produção avícola, referem-se à deposição de ácido, aquecimento global e efeitos locais e regionais da emissão de odores (BADO, 2006). Os resíduos são depositados em um terreno próximo ao curso d'água (riacho) que deságua no açude Jatobá II, além disso, o terreno fica ao lado da PB-306, provocando desconforto também aos motoristas que trafegam pelo local (Figura 6).

No período chuvoso os dejetos são carreados para o riacho que passa ao lado do local, onde são depositados os resíduos, contribuindo com a poluição e contaminação das águas. De acordo com Chapman (1996) embora os principais componentes presentes nos resíduos animais forneçam nutrientes para as plantas, também estão relacionados com a contaminação das águas subterrâneas e de superfície. Além disso, substâncias que demandam oxigênio, materiais em suspensão e patógenos oriundos do inadequado gerenciamento dos resíduos da produção avícola, carreados para corpos d'água, podem alterar ou contaminar o ambiente (BADO, 2006). 
Figura 6 - Local onde são depositados os resíduos dos aviários no município de Princesa Isabel-PB.

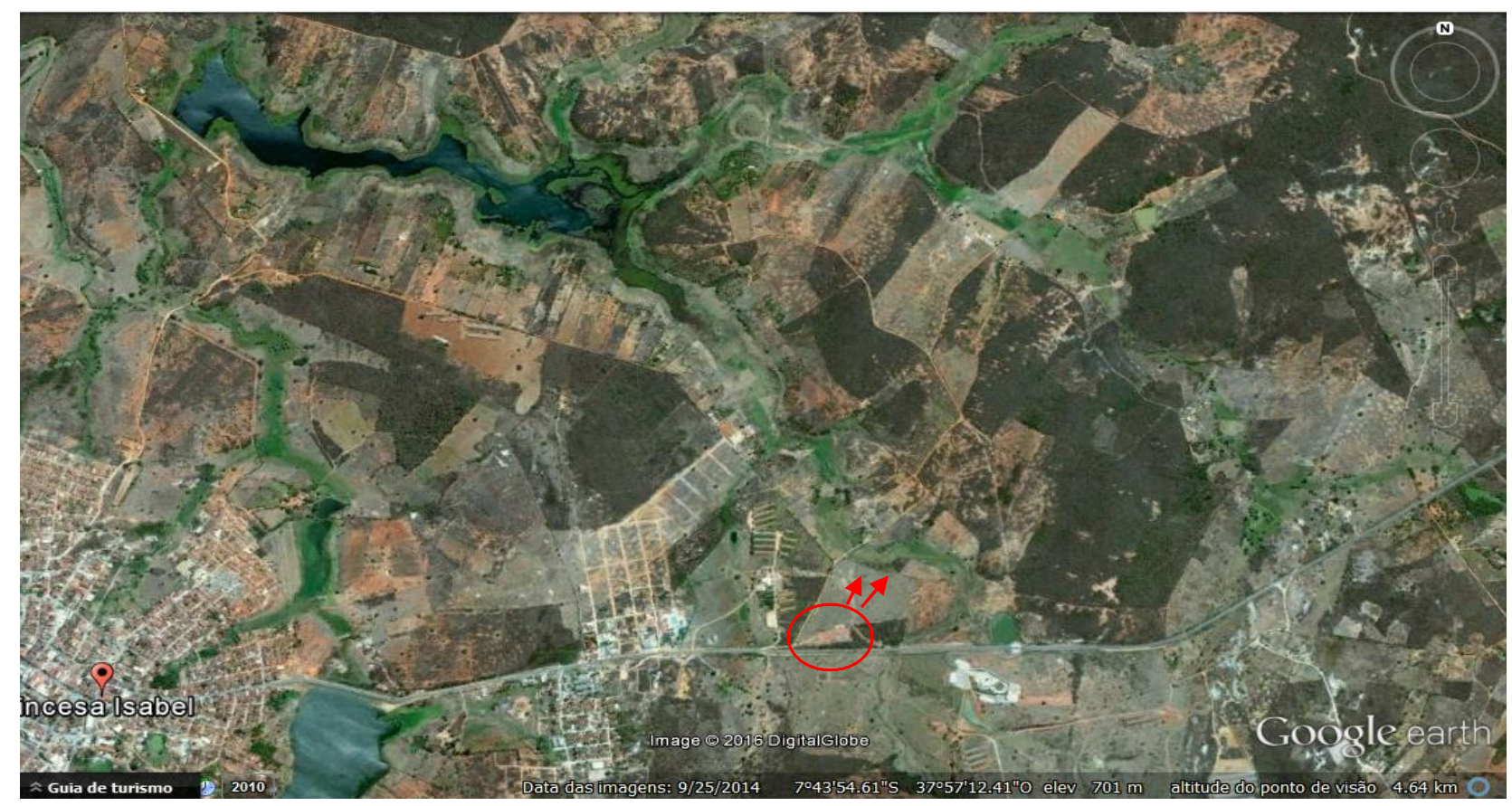

Fonte: Google Earth (2016).

Para Bado (2006) o enriquecimento excessivo de águas superficiais com nitratos e derivados nitrogenados pode levar ao desequilíbrio dos ecossistemas aquáticos devido ao processo de eutrofização, que consiste da proliferação exagerada de algas e plantas aquáticas. Esse mesmo autor afirma que, a amônia dissolvida na água, pode ser tóxica para peixes mesmo em baixas concentrações.

Perguntados sobre quem são os responsáveis pelos problemas ambientais, 21,5\% dos entrevistados responderam que é o poder público, 50\% afirmaram que são os moradores, 14,3\% indicaram que a responsável é a natureza, $7,1 \%$ não sabem quem são os responsáveis e 7,1\% disseram que os responsáveis são todos (poder público, moradores e a natureza) (Figura 7).

Figura 7- Responsáveis pelos problemas ambientais no entorno do açude Jatobá II no município de Princesa Isabel-PB.

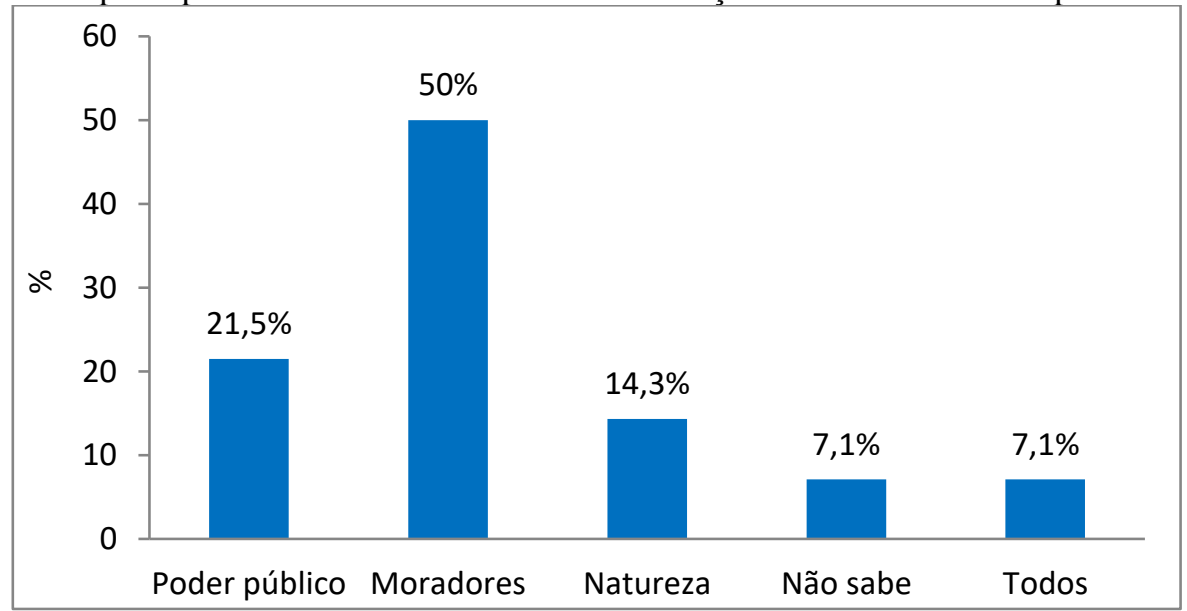

Fonte: Elaborado pelos autores (2016). 
$\mathrm{O}$ acesso a informações sobre o meio ambiente ocorre de forma variada onde $64,3 \%$ dos entrevistados informaram ter acesso por meio da televisão, 7,1\% afirmaram ser por meio do jornal, $7,1 \%$ disseram ter acesso à informação pelo rádio e $21,5 \%$ através de outros meios de comunicação (Figura 8).

Figura 8 - Acesso a informação sobre meio ambiente pelos moradores.

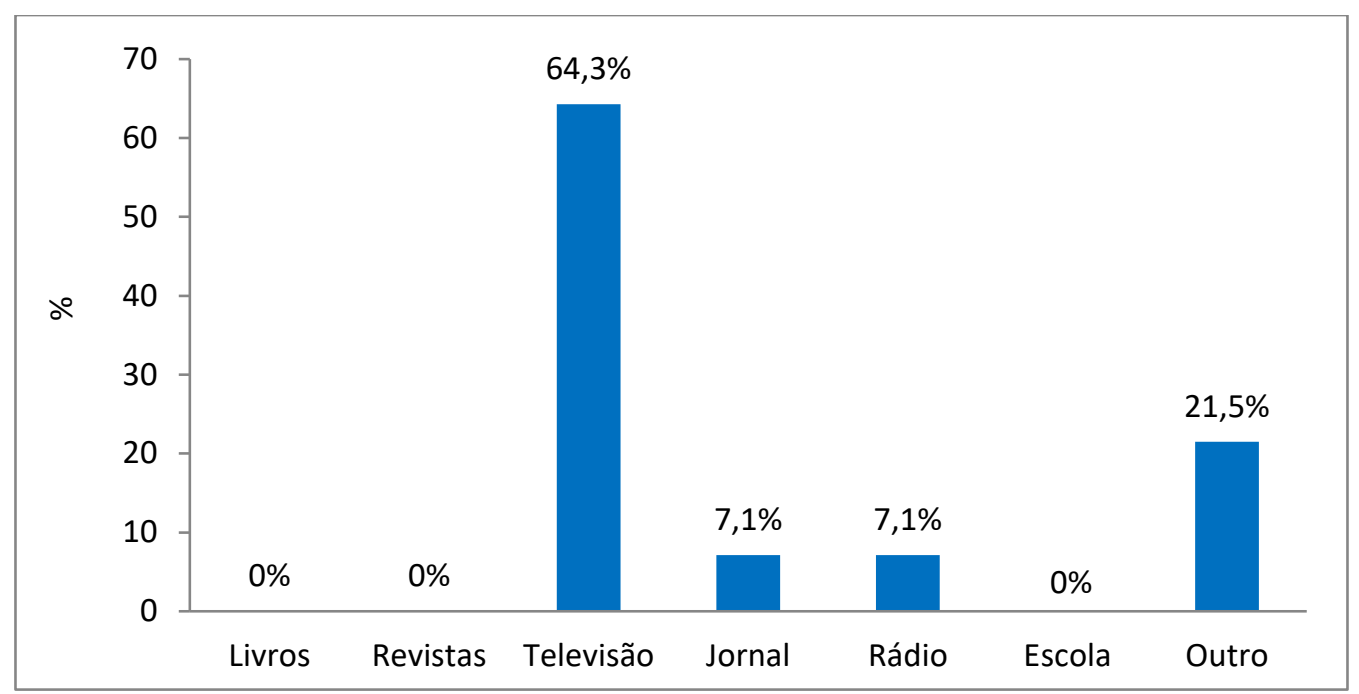

Fonte: Elaborado pelos autores (2016).

Sobre o desmatamento no município, quando perguntados se existiam áreas desmatadas 42,9\% indicaram que sim, enquanto que, 57,1\% responderam que não (Figura 9). Apesar da maioria dos entrevistados responderem que não existem áreas desmatadas no entorno do açude e/ou no município, esse dado reflete um cenário contrário ao que foi verificado durante o trabalho de campo, onde foram encontradas áreas desmatadas nas imediações do açude, bem como no município.

Figura 9- Desmatamento na área municipal, segundo os moradores do entorno do açude Jatobá II.

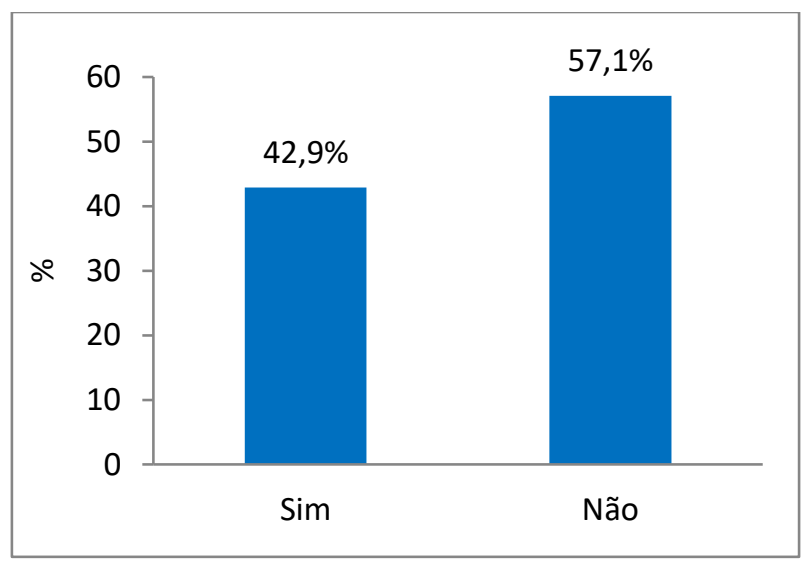

Fonte: Elaborado pelos autores (2016). 
Procurados se conheciam animais silvestres na área municipal, 42,9\% dos entrevistados responderam que conhecem animais silvestres e que eram mais comuns de serem vistos no passado, 57,1\% afirmaram que não conhecem (Figura 10).

Figura 10 - Conhecimento sobre a existência de animais silvestres no município de Princesa Isabel-PB.

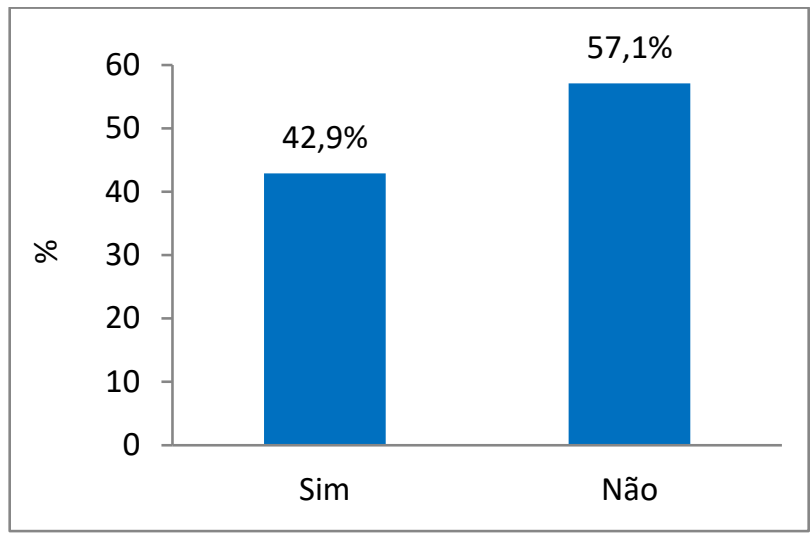

Fonte: Elaborado pelos autores (2016).

Questionados sobre quem deveria resolver os problemas ambientais, $71,4 \%$ dos entrevistados disseram que o governo deveria resolver, 21,5\% afirmaram que a comunidade deveria resolver e 7,1\% responderam que as escolas deveriam resolver (Figura 11).

Figura 11 - Resolução dos problemas ambientais no entorno do açude Jatobá II.

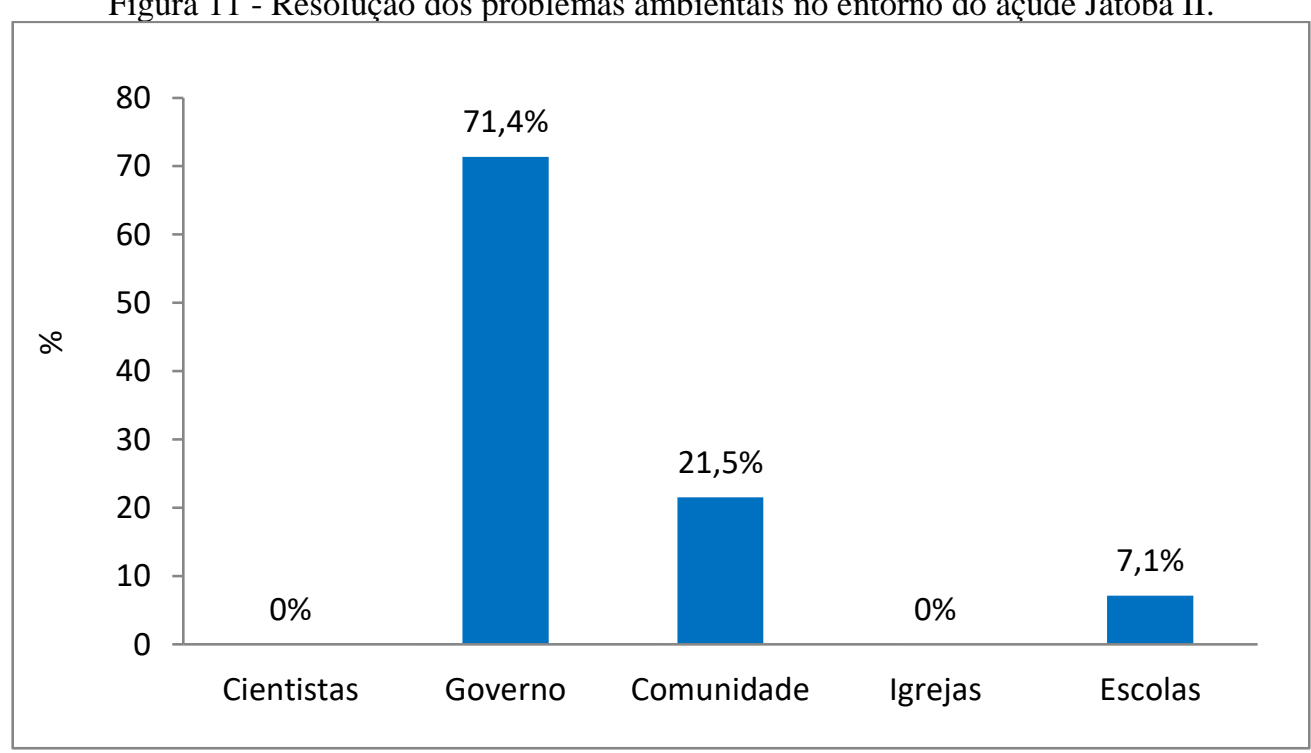

Fonte: Elaborado pelos autores (2016).

Os problemas ambientais no entorno do açude Jatobá II são evidentes, porém, ao serem questionados se já haviam denunciado alguma ocorrência ou poluição, 100\% dos entrevistados responderam que não e/ou nunca denunciaram, mesmo sendo afetados (Figura 12). 
Revista de Geografia (Recife) V. 36, No.3, 2019 - ISSN: 2238-6211

Figura 12 - Denúncia de ocorrência de problemas ambientais no entorno do açude.

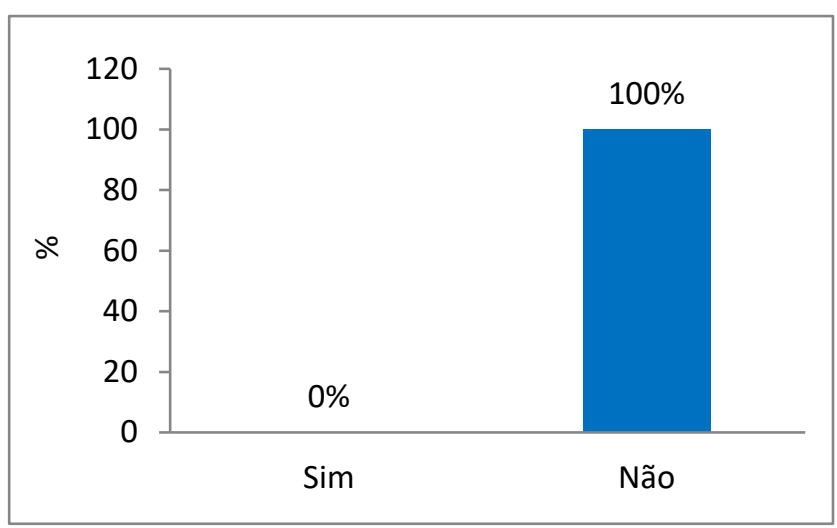

Fonte: Elaborado pelos autores (2016).

Quando perguntados se participariam de alguma ação para melhorar o meio ambiente 64,3\% disseram que sim, 35,7\% afirmaram que não participariam (Figura 13). Esse dado é preocupante tendo em vista os diversos problemas existentes nessa área e que merecem atenção por parte da população.

Figura 13 - Participação em ações sobre meio ambiente pelos moradores do entorno do açude.

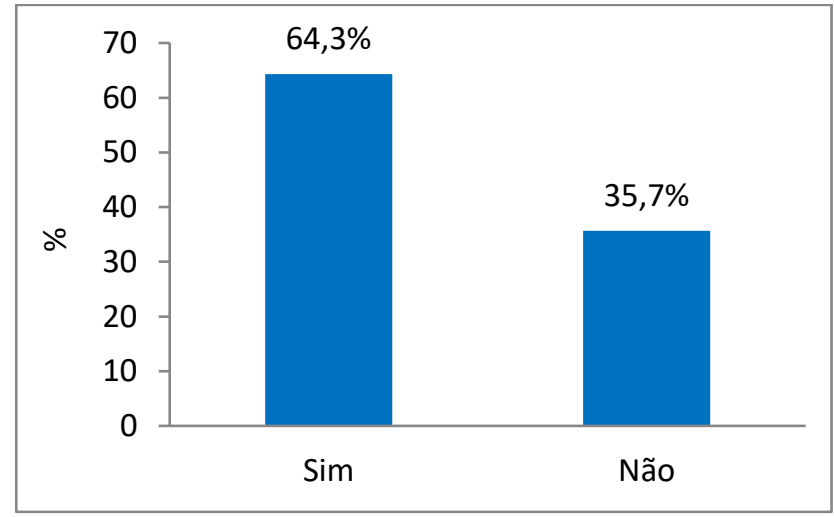

Fonte: Elaborado pelos autores (2016).

Embora, a maioria dos entrevistados respondendo que participariam de ações voltadas ao meio ambiente, muitas pessoas foram contrárias a ações desta natureza, mostrando indiferença com as questões ambientais.

\section{Principais mudanças ocorridas no entorno do açude Jatobá II segundo os moradores}

Com relação às principais mudanças ocorridas no entorno do açude Jatobá II, no período em que residem na área 14,3\% dos entrevistados afirmaram que foram construídas cercas dentro do açude, $7,1 \%$ disseram que a principal mudança foi o assoreamento no açude, $7,1 \%$ indicaram que existem muitos animais soltos nas imediações do açude, 42,9\% ressaltaram que a principal mudança é a falta d'água no açude, 7,1\% responderam que houve redução da vegetação e 21,5\% afirmaram não ter notado e/ou observado nenhuma mudança (Figura 14). 
Figura 14- Principais mudanças ocorridas no açude Jatobá II, conforme os moradores.

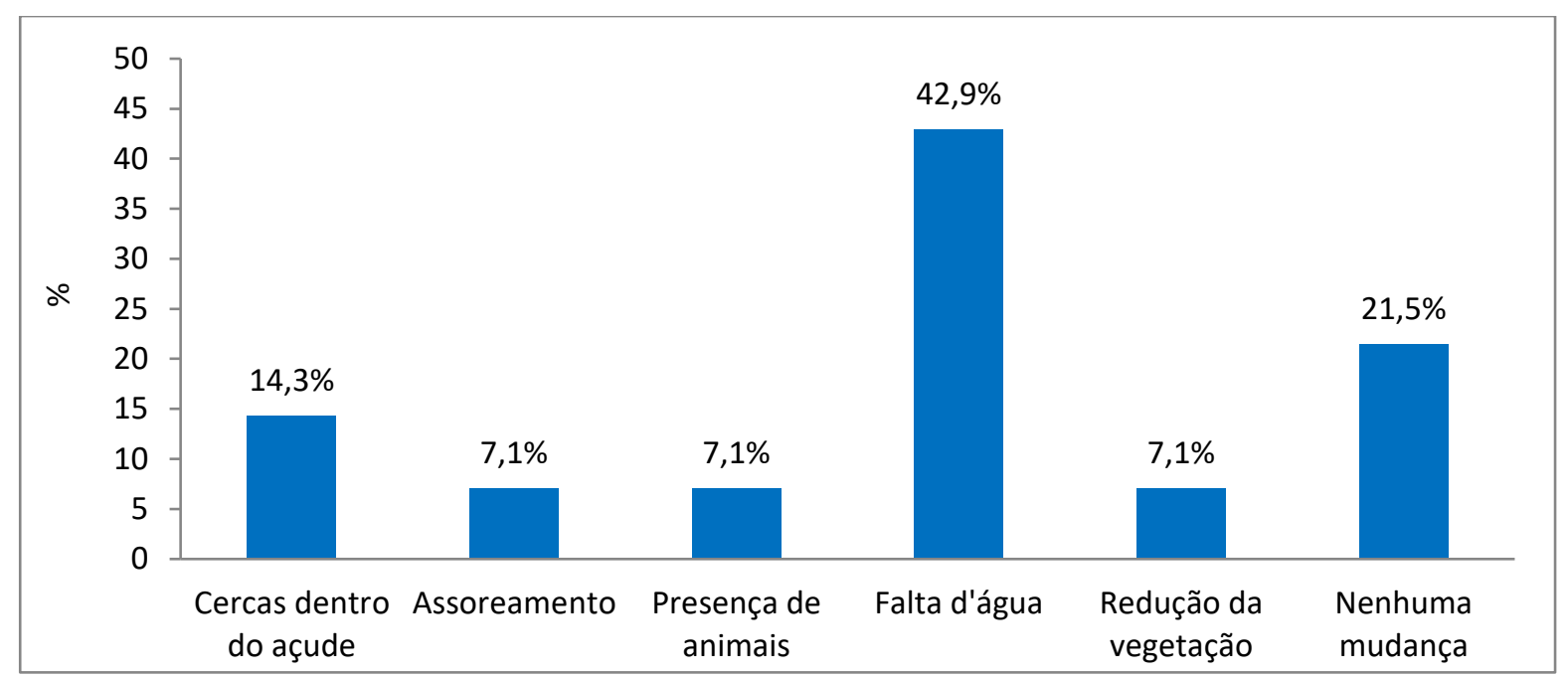

Fonte: Elaborado pelos autores (2016).

Durante o trabalho de campo evidenciou-se em diferentes pontos do açude a presença de cercas, delimitando e separando o reservatório. Essa é uma atividade irregular, que é realizada por muitos produtores que possuem terras nas proximidades do manancial (Figura 15).

Figura 15- Cercas delimitando a área e plantação de milho e feijão dentro do açude Jatobá II.

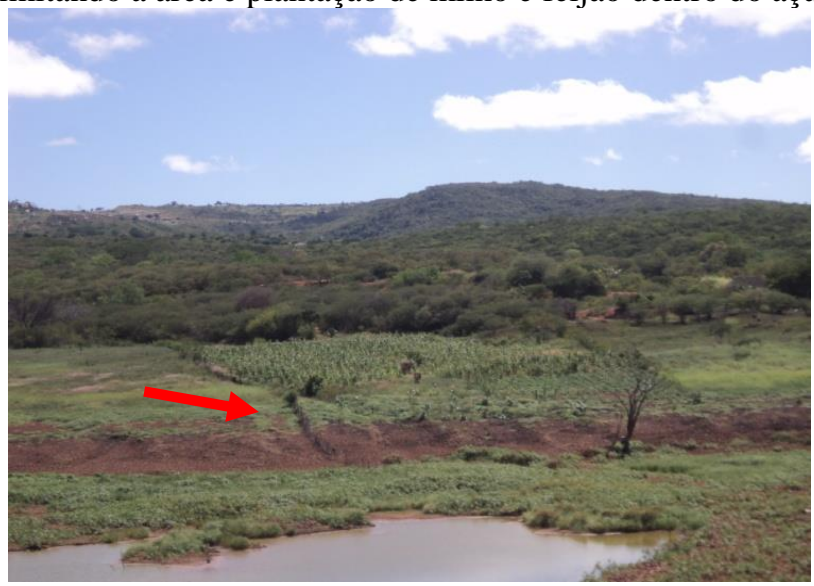

Fonte: A autora (2016).

Essas atividades desrepeitam a resolução $n^{\circ} 302 / 2002$ do Conselho Nacional de Meio Ambiente (CONAMA) ${ }^{1}$, que caracteriza os reservatórios artificiais $^{2}$ como Áreas de Proteção Permanente ${ }^{3}$. O artigo $3^{\circ}$ da mesma resolução estabelece que:

\footnotetext{
${ }^{1}$ Dispõe sobre os parâmetros, definições e limites de Áreas de Preservação Permanente de reservatórios artificiais e o regime de uso do entorno.

${ }^{2}$ De acordo com o artigo $2^{\circ}$ da Resolução $n^{\circ}$ 302/2002 do CONAMA, Reservatório artificial é a acumulação não natural de água destinada a quaisquer de seus múltiplos usos.

${ }^{3}$ De acordo com o artigo $2^{\circ}$ da Resolução $n^{\circ}$ 302/2002 do CONAMA, Área de Preservação Permanente: a área marginal ao redor do reservatório artificial e suas ilhas, com a função ambiental de preservar os recursos hídricos, a paisagem, a estabilidade geológica, a biodiversidade, o fluxo gênico de fauna e flora, proteger o solo e assegurar o bem estar das populações humanas.
} 
Art. $3^{\circ}$ - Constitui Área de Preservação Permanente a área com largura mínima, em projeção horizontal, no entorno dos reservatórios artificiais, medida a partir do nível máximo normal de: I - trinta metros para os reservatórios artificiais situados em áreas urbanas consolidadas e cem metros para áreas rurais $[\ldots]$.

O assoremento é visível no açude, o qual apresenta bancos de terra por toda a extensão, principalmente nas proximidades da parede do reservatório, ocasionando na diminuição da capacidade de arrmazenamento. A falta d'água é perceptível no município principalmente nas proximidades do manancial, bem como, a redução da vegetação (Figura 16).

Figura 16- A) Bancos de terra nas proximidades da parede do açude e B) Assoreamento na parte central do reservatório.
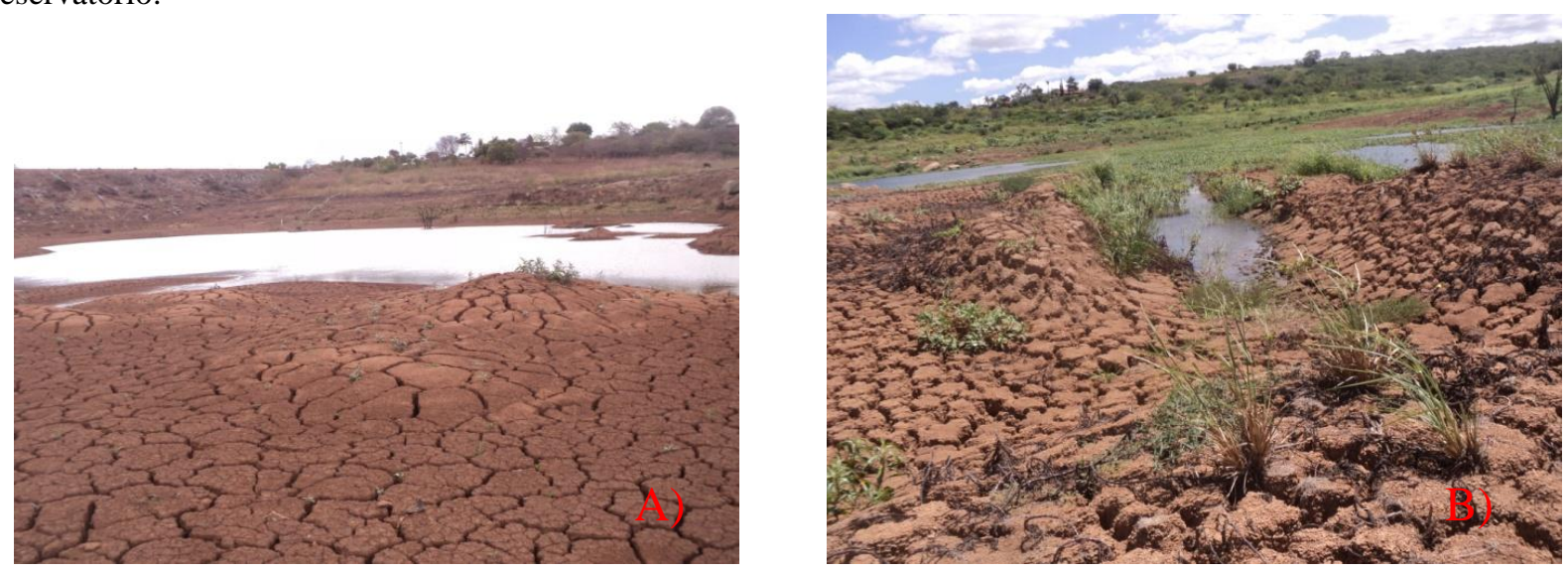

Fonte: A autora (2016).

A presença de animais é comum nas imediações do açude, sendo bovinos, equinos e caprinos. Estes são criados soltos às margens do açude provocando a compactação do solo por meio do pisoteio, outro problema são os resíduos deixados pelos animais, que podem poluir a água (Figura 17).

Figura 17- A) Animais soltos nas imediações do açude e B) Bovinos criados nas proximidades do reservatório.
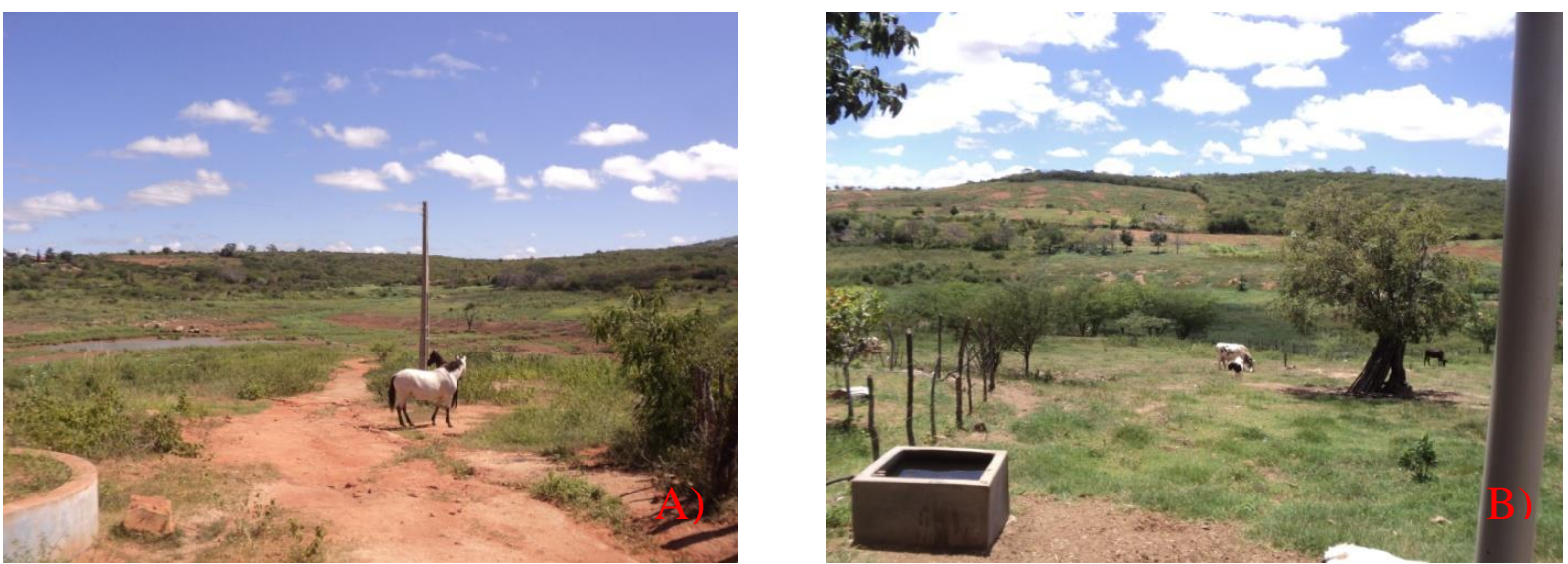

Fonte: A autora (2016). 
A vegetação desempenha papel importante na natureza, entretanto, no entorno do açude a retirada da vegetação é vísivel, sobre isso, questionados se a retirada da mata no entorno do açude Jatobá II prejudicava o açude, 71,4\% dos entrevistados disseram que sim, 21,5\% afirmaram que não e $7,1 \%$ não sabem (Figura 18).

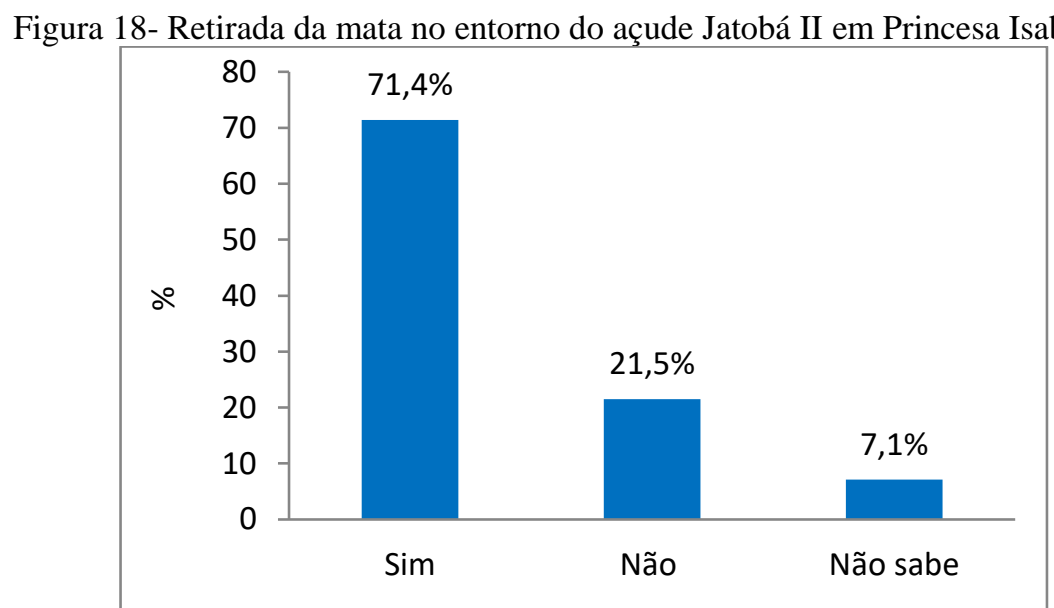

Fonte: Elaborado pelos autores (2016).

Com relação à educação ambiental, os dados obtidos chamam a atenção para o desconhecimento sobre esse tema, onde $92,9 \%$ dos entrevistados responderam que não sabem o que é educação ambiental e 7,1\% disseram que sabem o que significa (Figura 19).

Figura 19 - Conhecimento sobre educação ambiental, segundo os habitantes do entorno do açude Jatobá II.

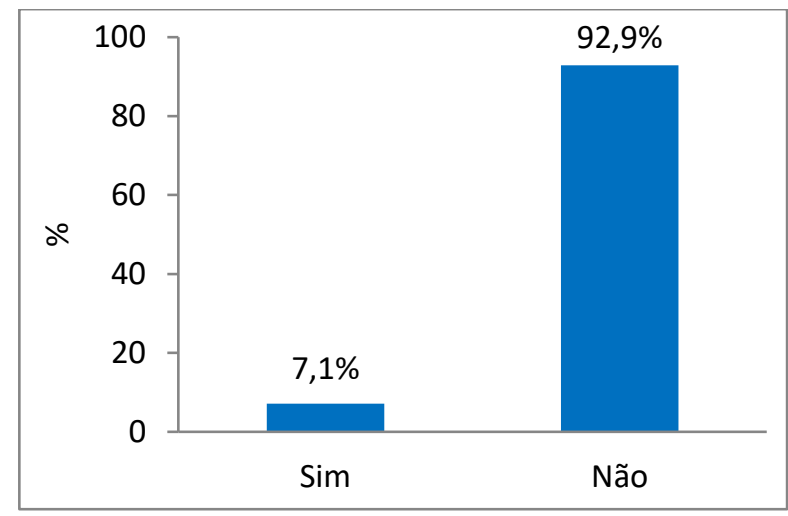

Fonte: Elaborado pelos autores (2016).

Esses dados mostram o nível de desconhecimento sobre temas e questões relevantes sobre o meio ambiente.

\section{CONSIDERAÇÕES FINAIS}

Os entrevistados demonstraram através da percepção ambiental as modificações ocorridas na área de acordo com sua vivência ao longo do tempo, sendo a seca um dos fatores mais 
percebidos pelos entrevistados. Mesmo com secas severas o açude Jatobá II permanecia sempre com água, porém, em 50 anos essa é a primeira vez que o reservatório seca completamente.

Outro fato percebido e mencionado pelos entrevistados foi o mau cheiro gerado pelas camas de galinha que são depositadas de forma inadequada em um terreno que fica ao lado de um dos afluentes que deságuam no açude Jatobá II, com as chuvas os dejetos escorrem em direção ao riacho. Essa é uma situação que merece atenção dos órgãos públicos, pois as camas de galinha liberam a amônia que de acordo com a literatura científica consultada pode gerar problemas de saúde se inalado em longo prazo.

O desconhecimento sobre temas relevantes favorece a permanência e ocorrência dos diversos problemas ambientais existentes no entorno do açude Jatobá II, prejudicando os moradores de forma direta e indireta.

\section{REFERÊNCIAS}

AESA - Agência Executiva de Gestão das Águas do Estado da Paraíba. Volumes. Disponível em: <http://www.aesa.pb.gov.br>. Acesso em: 12 nov. 2015.

AESA - Agência Executiva de Gestão das Águas do Estado da Paraíba. Últimos Volumes. Disponível em: <http://www.aesa.pb.gov.br/aesa-website/monitoramento/ultimos-volumes/>. Acesso em: 25 nov. 2019.

BADO, C. Gestão de resíduos resultantes da produção de frangos de corte. Dissertação (Mestrado em Geografia) - Universidade Estadual de Maringá. Maringá-PR, 2006. 74p.

BRASIL. Ministério da Agricultura. Escritório de Pesquisa e Experimentação. Equipe de Pedologia e Fertilidade do Solo. I. Levantamento exploratório-reconhecimento de solos do Estado da Paraíba. II. Interpretação para uso agrícola dos solos do Estado da Paraíba. Rio de Janeiro, 1972. 683 p. (Brasil. Ministério da Agricultura. EPFS. Boletim Técnico, 15; SUDENE-DRN. Série Pedologia, 8).

CARVAlHO, A. P; RODRIGUES, M. A. N. Percepção ambiental de moradores no entorno do açude Soledade no estado da Paraíba. Revista Eletrônica em Gestão, Educação e Tecnologia Ambiental, v. 11, p. 25-35, 2015.

CONAMA. RESOLUÇÃO CONAMA N 302, DE 20 DE MARÇO DE 2002. Disponível em: <http://licenciamento.cetesb.sp.gov.br/legislacao/federal/resolucoes/2002_Res_CONAMA_302.pd 
f>. Acesso em 23 de junho de 2016.

CHAPMAN, S. L. Soil and solid poultry waste nutrient management and water quality. Poultry Science, v. 75, p. 862-6, 1996.

FERNANDES, R. S; SOUZA, V. J; PELISSARI, V. B; FFERNANDES, S. T. Uso da percepção ambiental como instrumento de gestão em aplicações ligadas às áreas educacional, social e ambiental. Rede Brasileira de Centros de Educação Ambiental. Rede CEAS. Noticias, 2009. Disponível em: <http://www.redeceas.esalq.usp.br/noticias/Percepcao_Ambiental.pdf>Acessado em: 12 out. 2016.

FERREIRA, J. C. Remoção de amônia gerada em granjas avícolas e sua utilização em células à combustível e uso como fertilizante. Tese (Doutorado em Ciências) - Instituto de Pesquisas Energéticas Nucleares, São Paulo, 2010. 147p.

FAgGiOnAto, S. Percepção ambiental. Materiais e Textos, 2011. Disponível em: <http://educar.sc.usp.br/biologia/textos/m_a_txt4.html>. Acesso em: 24 jun. 2016.

GOOGLE. Google Earth. 2016. Disponível em: <http://earth.google.com/>. Acesso: 01 jan. 2016.

IBGE - Instituto Brasileiro de Geografia e Estatística. Resultados Preliminares do Universo do Censo Demográfico 2010. Disponível em: 〈http://www.ibge.gov.br/cidadesat/topwindow.htm?1〉. Acesso em: 03 fev. 2016.

IBGE. Instituto Brasileiro de Geografia e Estatística. (2009). Disponível em <http://www.ibge.gov.br>. Acesso em 12 Set. 2016.

MASCARENHAS et al., (2005). Projeto Cadastro de Fontes de Abastecimento por água subterrânea Estado da Paraíba: Diagnóstico do município de Princesa Isabel, estado da Paraíba/Organizado por João de Castro Mascarenhas, Breno Augusto Beltrão, Franklin de Morais, Jorge Luiz Fortunato de Miranda, Luiz Carlos de Sousa Junior, Vanildo Almeida Mendes. Recife. CPRM/PRODEEM, 2005, 19p.

MELAZO, G. C. Percepção Ambiental e Educação Ambiental: uma reflexão sobre as relações interpessoais e ambientais no espaço urbano. Revista Olhares e Trilhas (UFU). Uberlândia-MG, ano IV, n. 6, p. 45-51, 2005. 